\title{
Revolución verde en los suelos agrícolas de México. Ciencia, políticas públicas y agricultura del maíz, 1943-1961
}

Green Revolution in the agricultural soils of Mexico. Science, public policy, and corn agriculture, 1943-1961

Netzahualcóyotl Luis Gutiérrez Núñez

DOI: https://doi.org/10.24215/15155994e142

División de Ciencias Sociales y Humanidades. Universidad Redalyc: http://www.redalyc.org/articulo.oa?id=84563515004 de Guanajuato-CONACYT, México

netzagtz@gmail.com

Recepción: 10 Octubre 2019

Aprobación: 24 Mayo 2020

\section{Resumen:}

El artículo analiza la labor de la Oficina de Estudios Especiales en la formación de las ciencias del suelo y para la creación de tecnologías fertilizantes para la agricultura del maíz en México. Estudia, además, las políticas públicas que implementó el Estado mexicano para la construcción de una industria de fertilizantes, así como los alcances y problemáticas de su difusión en el cultivo del maíz en el Occidente de México.

Palabras clave: Maíz, Revolución verde, Ciencias del suelo, Fertilizantes, Políticas públicas, México.

\section{Abstract:}

The article analyzes the work of the Office of Special Studies in the formation of soil sciences and the creation of fertilizer technologies for corn agriculture in Mexico. It also studies the public policies that the Mexican State implemented for the construction of the fertilizer industry, as well as the scope and problems of its spread in the cultivation of corn in Western Mexico. KEYwords: corn, Green Revolution, Soil Sciences, Fertilizers, public policies, Mexico.

\section{INTRODUCCIÓN}

Entre 1943 y 1961 funcionó en México la Oficina de Estudios Especiales (en adelante OEE), institución cofinanciada por la Fundación Rockefeller y la Secretaría de Agricultura y Ganadería (SAG). Su objetivo era transformar la agricultura mexicana por medio de innovaciones que abarcaban un amplio conjunto de cultivos (Stakman et al., 1967, pp. 2-16). En términos historiográficos, la labor de la OEE ha sido objeto de debate desde los años setenta. Por aquellos años eran comunes interpretaciones que o bien ensalzaban los logros de los científicos estadounidenses que trabajaron en esa institución, o bien los denostaban, por su olvido de la agricultura campesina o porque los consideraban un instrumento de la expansión imperialista estadounidense (Stakman, Bradfield \& Mangelsdorf, 1967; Cleaver, 1972, pp. 177-186). En las tres últimas décadas diversos estudios han revisado la trascendencia de los trabajos de innovación de la OEE, y han recuperado sus logros, pero sin soslayar sus repercusiones negativas tanto económicas, como políticas o medioambientales. ${ }^{1}$

En esa revisión de la Revolución Verde han sido de gran valor los estudios que desde la historia de la ciencia han iluminado la genealogía de las innovaciones biológicas, químicas y mecánicas, con particular énfasis en las primeras (Mattchet, 2002). Asimismo, similar importancia han tenido las perspectivas agrarias y ambientales que han ido más allá de los resultados macroeconómicos de la Revolución Verde, para explicar dónde, cómo y quiénes aplicaron las innovaciones que constituyeron el denominado paquete tecnológico: semillas mejoradas, fertilizantes, pesticidas y maquinaria (Lorek, 2019; Gutiérrez, 2017). La relevancia de lo anterior queda expuesta si se piensa que la agricultura se realiza en un nicho ecológico concreto: en cierto clima, con cierto régimen pluviométrico o acceso hídrico, y en un medio edáfico determinado. 
Con respecto al medio edáfico, la historiografía de la Revolución Verde ha puesto poca atención al tema; esto se dio a pesar de que sus características - grosor, características fisicoquímicas y biología- tienen una gran influencia en el desarrollo de los cultivos y sus rendimientos. Si bien es cierto que las semillas mejoradas eran las innovaciones estelares de la OEE, que alcanzaran altos rendimientos dependía de la disponibilidad de nutrientes en el suelo (Stakman et al., 1967, p. 8). Para lograrlo, los científicos de la OEE desestimaron alternativas basadas en el reciclaje de nutrientes orgánicos, e impulsaron la introducción a los ecosistemas agrarios de derivados de la petroquímica, sobre todo a partir de los años cincuenta, tal como lo ha señalado Angus Wright. En general, si seguimos a este autor, se podría plantear la hipótesis de que entre los años cincuenta y sesenta se inició un proceso de rápida expansión de la agricultura de base inorgánica en México (Wright, 2012, pp.36 y 37).

Lo que me propongo en este artículo es analizar tres componentes de ese proceso de expansión de la agricultura de base inorgánica, tomando como caso de estudio el maíz. El primer componente será la ciencia. ¿Por qué los científicos de la OEE impulsaron los fertilizantes químicos y no otras alternativas basadas en el reciclaje de materia orgánica?. Como veremos, esto se debió a cómo concebían el suelo agrícola a través de una percepción que se construyó durante la primera mitad del siglo XX. El segundo elemento será la industria de fertilizantes. En el caso mexicano, como se verá, una industria de fertilizantes paraestatal se desarrolló a fines de los años cuarenta del siglo pasado, apoyada en el plano científico-técnico por los estudios de la OEE. Un tercer elemento son las políticas públicas dirigidas por el gobierno federal mexicano para la difusión de los fertilizantes en la agricultura del maíz. A través de esas políticas es que podremos observar dónde y cómo se difundieron, a la vez que podremos revisar algunas problemáticas que enfrentaron. Cabe aquí señalar una limitante del estudio: no revisaremos, por no disponer de fuentes para ello, el papel que jugaron empresas y casas comerciales en la difusión de fertilizantes. No obstante, en lo que se pretende poner énfasis en este trabajo es sobre la relación que se estableció entre investigación científica y Estado en el caso de las ciencias del suelo y la difusión de innovaciones químicas para incrementar la productividad agrícola a mediados del siglo pasado en México.

Antes de iniciar debemos clarificar dos cosas. ¿Por qué el maíz? Para el período de estudio el maíz no solo representaba el cereal de mayor consumo en México, también su producción tuvo un incremento significativo entre 1940 y 1965, cuando pasó de 1,6 a 8,5 millones de toneladas anuales; es decir, creció a una tasa de $7 \%$ anual (Gutiérrez, 2017,pp. 93-95). ¿Cuál fue el papel que jugaron los fertilizantes químicos en ese incremento en la región que nos ocupa? La segunda es sobre el espacio de estudio. Dada la complejidad y diversidad geográfica de la agricultura mexicana, he delimitado el espacio de estudio a tres estados ubicados en el centro occidente de México: Guanajuato, Jalisco y Michoacán (mapa 1). 
MAPA 1

Ubicación en el territorio mexicano de los estados de Guanajuato, Jalisco y Michoacán

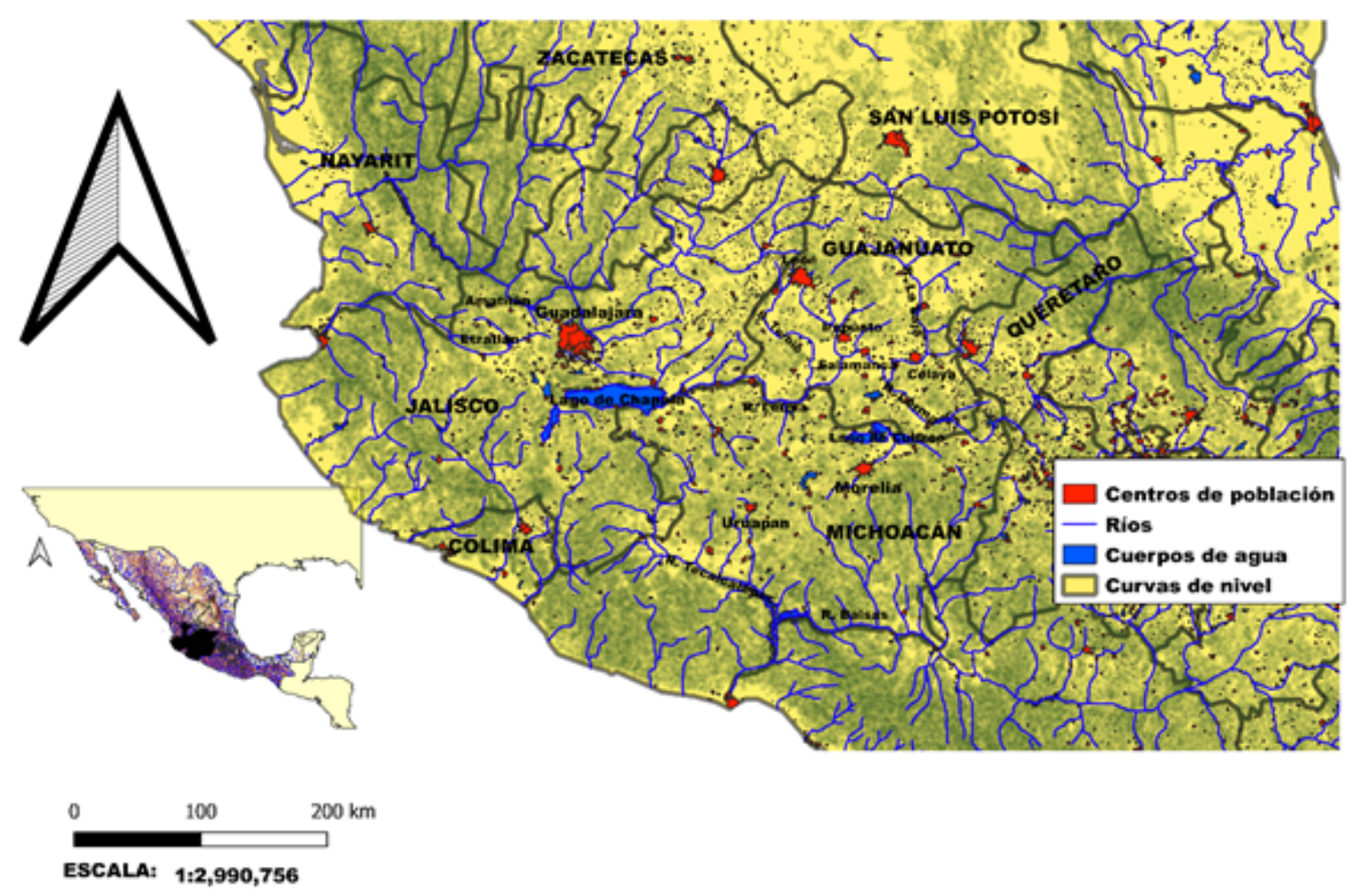

Fuente: elaboración propia

La importancia de estos estados de la república para la agricultura del maíz radica en que entre 1940 y 1960 los tres sumaron entre una cuarta y una quinta parte de la producción nacional. Asimismo, como veremos, en Jalisco el gobierno federal implementó el primer plan de tecnificación basado en las innovaciones de la OEE con miras a que fuera uno de los bastiones de la anhelada autosuficiencia alimentaria.

\section{¿QUÉ ES EL SUELO AGRÍCOLA? DOS CONCEPCIONES, DOS FORMAS DE ENTENDER LA AGRICULTURA}

La reposición de los nutrientes del suelo y, más que eso, alcanzar un superávit en cada ciclo agrícola ha sido un elemento primordial de cada episodio de cambio tecnológico en la agricultura (Garrabou, 1994, p. 102). Un problema clave es entender cómo se percibe en cada episodio de cambio al suelo agrícola, porque ello permite explicar de qué manera se actúa sobre él para reponer los nutrientes. Así, en nuestro caso, ¿̇cuál sería la concepción del suelo agrícola que tenían los científicos estadounidenses de la OEE? ¿Cómo fue que se impuso en instituciones académicas y gubernamentales estadounidenses una concepción que se inclinó por el uso de fertilizantes químicos?

Las ciencias del suelo estadounidenses se constituyeron como tales en la segunda mitad del siglo XIX. En ese período de tiempo, como lo han mostrado diversas investigaciones, se conformaron diversas disciplinas agronómicas en el marco de una intensa circulación de conocimientos y agentes a nivel global. En el caso de las ciencias del suelo estadounidenses, estas recibieron influencias de sus similares rusas, que estuvieron a la vanguardia hasta los años treinta del siglo pasado (Fitzgerald, 1996, pp. 461 y 462). 
Tres científicos rusos construyeron un enfoque sobre los suelos agrícolas que combinaba el análisis geológico con el de su biología: Vasily Dokuchaev, Dmietrievich Glinka y Sergei Winogradsky. El primero investigó los suelos agrícolas ucranianos, observando una estructura por horizontes, con variaciones en su composición física, química y biológica. Concluyó, además, que los suelos se formaban a partir de la interacción entre el sustrato geológico, las condiciones medioambientales, organismos vivos y sus despojos en descomposición. Años más tarde, Dmietrievich Glinka, alumno de Dockuchaev en la Universidad de San Petersburgo, estudió cuatro factores condicionantes para el desarrollo de los suelos en Kazajstán: humedad, desecado, clima, vegetación y materiales geológicos. (Legros, 2011, pp. 381 y 383). Por su parte, Sergei Winogradsky estudió el rol que cumplen los organismos unicelulares en el medio edáfico, y encontró que en sus procesos metabólicos intercambian nutrientes y gases con las plantas. Lo anterior sucede en ausencia de oxígeno o luz solar, fenómeno que Winogradsky denominó quimiosíntesis, para diferenciarla de la fotosíntesis (Ackert, 2006, p. 115). Sus hallazgos revelaron que los suelos eran parte de un gran sistema -"el ciclo de la vida”, como le llamó- que vinculaba, por un lado, a los reinos biótico y abiótico, y, por otro, a lo microscópico con lo macroscópico a través de "un complejo intercambio de materia y la transformación de energía" (Dworkin, 2012, pp. 371 y 372).

La obra de los científicos rusos alentó una polémica en torno a cómo se concebía al medio edáfico agrícola y a la manera de renovar sus nutrientes. Dicha polémica provenía de la práctica agrícola estadounidense en el siglo XIX. Durante la primera mitad de esa centuria se habían conformado dos modelos de agricultura: el primero intensivo, variante de los sistemas constituidos en Inglaterra durante la primera revolución agrícola, sobre todo del Norfolk; el segundo, extensivo, resultado de la constante expansión hacia la costa del Pacífico. En el sistema extensivo el suelo era concebido como un recurso que podía ser sustituido en caso de disminuir su productividad (Stoll, 2003, pp. 5-23). No obstante, la expansión hacia el oeste no duraría por siempre, y las reservas de suelos vírgenes se fueron agotando. Ya para la década de 1880, tanto en la iniciativa privada como en las instituciones públicas relacionadas con la agricultura, se hizo evidente la intención de promover tecnologías más eficaces para incrementar la productividad en las tierras en explotación (Kellogg, 1957, pp. 4 y 6). En cuanto a las instituciones, en el United States Department of Agriculture (USDA), Milton Whitney -director del Departamento del Suelo entre 1860 y 1927-promovió la realización de estudios para mapear los suelos agrícolas estadounidenses con base en su composición fisicoquímica. Además de lo anterior, Whitney investigó sobre la disminución de la fertilidad en suelos agrícolas, y planteó que se debía a un proceso de "autoenvenenamiento" provocado por la abundancia de ciertos compuestos químicos en el suelo producidos por bacterias y por las mismas plantas. Este problema, según Whitney, se resolvería con la aplicación de fertilizantes químicos (Willis, 2007, p. 219). En suma, Whitney promovió desde el USDA una perspectiva que privilegiaba los fenómenos fisicoquímicos de los suelos, esto es, un enfoque geológico; además, impulsaba el uso de los fertilizantes no solo para renovar nutrientes, sino también para resolver problemas fitopatológicos.

Al interior del USDA, sin embargo, la posición de Whitney generaba disensión. Eugene Hilgard, por un lado, planteó, más o menos en la misma época que sus contemporáneos rusos, que el suelo era un organismo vivo "en constante interacción con otros aspectos del ambiente natural" (Brevik, Fenton \& Homburg, 2016, p. 115). Hilgard no solo compartía su visión sobre el medio edáfico con los científicos rusos, también amistad, en particular con Glinka. Profesor de Agricultura en la Universidad de Berkeley y empleado del U. S. Geological Survey del USDA en California, Hilgard sostuvo una discusión con Whitney respecto a su concepción fisicoquímica y a su énfasis en los fertilizantes como tecnología para sostener la fertilidad de los suelos. Tal discusión se dirimió en términos jerárquicos, ya que la prolongada estadía de Whitney al frente de la Dirección de Suelos del USDA frenó la difusión de las ideas de Hilgard (Brevik et al., 2016, p. 115).

Pero no solo Hilgard estuvo en desacuerdo con Whitney. El presidente de la Asociación de Química Agrícola, Cyril Hopkins, afirmó que las tesis de Whitney no eran concluyentes y que más bien se valoraban por una cuestión de estatus y jerarquía (Paull, 2006, pp. 19-21). Una crítica a las ideas de Whitney con 
argumentos más precisos la planteó Franklin Hiram King, funcionario del Departamento de Estudios del Suelo. Para Hiram, la postura de Whitney de añadir nutrientes químicos exógenos al sistema agrario no era la mejor opción. Con base en sus investigaciones realizadas en China y Japón, Hiram sostenía que la solución era la "agricultura perenne", sistema basado en el reciclaje de los desperdicios orgánicos producidos por los seres humanos, que permitiría dar sustentabilidad a los cultivos (Heckman, 2013, 2798). De nuevo, la posición de Whitney detuvo las ideas de King y se mantuvo la hegemonía del enfoque geológico del suelo.

A pesar del freno institucional las ideas de Hilgard y King no se perdieron. En los años treinta dos fenómenos incidieron en que iniciara su paulatina difusión en instituciones educativas y en el USDA. Por un lado, la crisis medioambiental que se produjo a partir de las intensas sequías que afectaron a los estados de Texas y Oklahoma, cuyos suelos delgados y erosionados fueron levantados por los vientos lo que produjo grandes masas de polvo -el denominado Dust Bowl (Worster, 2004, pp.12-25)-. Por otro, un cambio generacional en la comunidad científica, con la incorporación de estudiosos como Charles Kellogg, James Thorp y Guy Smith, que además fueron funcionarios de alto rango del USDA (Brevik et al., 2016, p. 121). Asimismo, el primer libro de texto que difundía las enseñanzas de Dokuchaev apareció en Estados Unidos hasta 1941 y, para los años sesenta, se comenzó a difundir el estudio y la práctica de la microbiología de suelos, de acuerdo con las tesis de Winogradsky y Hilgard (Brevik et al., 2016, p. 118) ${ }^{2}$.

No obstante, a pesar de los avances de los enfoques microbiológicos en las ciencias del suelo, el enfoque geológico ligado a la fertilización química siguió prevaleciendo tanto en la ciencia y en la educación superior, así como en la agricultura intensiva, que se expandía de la mano de la urbanización y de los cambios en la dieta hacia un mayor consumo de proteínas, grasas y azúcares (Kellogg, 1957, p. 9). En este contexto, la fertilización se consideró como un elemento nodal para elevar los rendimientos, y el modelo que prevaleció fue uno extractivo, más preocupado por los flujos de entrada y salida -metáfora de las fábricas- que uno basado en el carácter cíclico, metabólico, de la agricultura. La gran beneficiaria de este dilema sería la industria de fertilizantes químicos. Este enfoque fue el que arribó a México de la mano de científicos estadounidenses en los años cuarenta del siglo pasado.

\section{LA Oficina de Estudios Especiales Y LAS investigaciones SOBRE LOS SUELOS AGRÍCOLAS MEXICANOS}

El establecimiento de la OEE tuvo como principal objetivo la modernización de la agricultura mexicana mediante la transferencia, adaptación y difusión de tecnologías y conocimientos agronómicos que se utilizaban en los sistemas agrícolas estadounidenses (Cotter, 1994, pp. 544-550). Con esa idea en mente, los directivos de la Fundación contrataron un conjunto de científicos estadounidenses, que se trasladaron a México entre 1943 y 1944: los fitopatólogos Elvis Stakman, George Harrar y Norman Borlaug; un genetista, Edwin Wellhausen, y un especialista en ciencias del suelo, William Colwell. Este último se encargaría de conformar las ciencias del suelo en México, así como de investigar las deficiencias del medio edáfico en la agricultura nacional con la finalidad de mejorar la cantidad de nutrimentos y elevar la productividad (Stakman et al, 1967, p. 40).

Desde su arribo y hasta 1946 E. Colwell trabajó en siete localidades, San Gaspar (Morelos), Cortázar (Guanajuato), Querétaro, Atlixco (Puebla), Santa Ana (Tlaxcala), San Andrés (D.F) y Tlaquepaque (Jalisco). En su opinión, los bajos rendimientos agrícolas se debían al atraso en las técnicas de cultivo, a la erosión y a la sobreexplotación de los suelos agrícolas por el monocultivo del maíz, además de que, en su mayoría, eran deficitarios en nitrógeno principalmente, y luego también en fósforo y en potasio (Colwell, 1947, p. 4). Para resolver esos problemas, según Colwell, la solución radicaba en las innovaciones mecánicas y químicas: se debían utilizar técnicas de cultivo que evitaran el arrastre del suelo por el agua y el viento; mientras tanto, los fertilizantes ayudarían a recuperar la capacidad perdida (Stakman et al., 1967, pp. 40 y 41). Con base en ese diagnóstico, el investigador estableció un esquema sobre las cantidades de fertilizantes adecuadas para el maíz: 
de 60 a 80 kilogramos de nitrógeno por hectárea y 80 de ácido fosfórico (equivalentes a entre 300 y 400 kilos de sulfato de amonio y 500 kilos de superfosfato). De esa manera -aseguraba el científico- los agricultores podrían obtener los rendimientos necesarios para costear los fertilizantes (Colwell, 1947, p. 4). Una ausencia en los experimentos y conclusiones de Colwell eran los factores medioambientales, y en particular el nivel de precipitaciones, a pesar de que el agua era un elemento vital para que los abonos pudieran funcionar de manera adecuada, y de que la agricultura de maíz en México se realizaba, en su mayor parte, bajo sistemas de secano.

A fines de los años cuarenta, Colwell retornó a los Estados Unidos, y fue sustituido por John Pitner doctorado por la Universidad de Iowa y profesor de la Universidad Estatal de Mississippi- al año siguiente. En general, Pitner llegó a similares conclusiones que Colwell: salvo dos regiones de México, el valle de Matamoros y la Ciénega de Chapala, el resto de los suelos nacionales debía ser intervenido con tecnologías diseñadas en la OEE, para lo que se requerirían investigaciones más amplias y a la vez más precisas en términos geográficos, climáticos y agroecológicas (Rockefeller Annual Report 1947, p. 132). Esta preocupación tenía que ver con la diversidad de contextos ecológicos en los que se realizaba la agricultura del maíz.

Pero también, la preocupación de Pitner por la diversidad y su impacto en las innovaciones agronómicas iba más allá de las ciencias del suelo (Gutiérrez, 2017, pp. 282-286) En efecto, la finalidad de que hubiera más nutrientes en el suelo era que plantas modificadas mediante la genética mendeliana pudieran absorberlas y convertirlas en una mayor cantidad de grano. Sin embargo, la diversidad geográfica y agroecológica, así como las sequías de fines de los cuarenta, fueron factores que impactaron de manera negativa en las primeras experiencias de difusión de semillas mejoradas, realizadas entre 1948 y 1951 por la Comisión Nacional del Maíz, institución que el gobierno federal estableció con esa función en 1947. Por tanto, desde 1951 la OEE inició un proceso de descentralización de las investigaciones en fitomejoramiento y fertilizantes, con el objetivo de que la eficiencia de las innovaciones en el campo aumentara y con ello se incrementara la producción maicera y se alcanzara la autosuficiencia alimentaria (Gutiérrez, 2017, pp. 282-286).

La OEE estableció estaciones experimentales en diferentes partes del país: El Bajío (en el estado de Guanajuato), Ciudad Obregón (Sonora), Cotaxtla (Veracruz) y el Altiplano Central (Texcoco, estado de México), a través de las estaciones experimentales Cal Grande, Ciudad Obregón, Cotaxtla y El Horno. Con más estaciones la OEE también requería de más personal, lo que se subsanó, por un lado, con la incorporación en 1951 de Reggie Laird, doctor en ciencias del suelo por la Universidad de Wisconsin; por otro, con jóvenes agrónomos mexicanos que desde los años cuarenta habían iniciado su entrenamiento. Entre estos últimos, algunos terminaron su formación en programas de maestría y doctorado en universidades del Este de los Estados Unidos (Stakman et al., 1967, pp. 9-11).

En los hechos, sin embargo, la descentralización tuvo sus límites en la internacionalización del programa agrícola de la Fundación Rockefeller, que inicio a partir de 1949 hacia diferentes países de América Latina y Asia. Desde ese momento dos ideas entraron en tensión: una que proponía construir modelos de modernización adecuados para cada nicho ecológico, y otra que los planteaba para regiones amplias, lo que homogeneizaba el uso de las nuevas prácticas agronómicas (Kay, 1993, pp. 3-8). En cuanto a la primera idea, el asunto era crear innovaciones que se pudieran adecuar no solo a la diversidad agroecológica, también a campesinos pobres que no podían sufragar el costo de los fertilizantes. Por lo anterior, Rodolfo Peregrina, Juan del Toro y Reggie Laird, de la OEE, pensaron en utilizar técnicas para conservar el suelo, como el labrado en contorno, combinado con el cultivo de plantas leguminosas que fijaban el nitrógeno atmosférico en el suelo (Peregrina, del Toro y Laird et al., 1955, p. 5)3. Sin embargo, la estrategia no dio el resultado esperado, puesto que la agricultura de subsistencia no tenía ni la cantidad, ni la calidad de suelos, ni los recursos hídricos para rotar tierras con dos o tres tipos de cultivos. Existía, además, otro impedimento. Según Carl Sauer, geógrafo de la Universidad de California en Berkeley, eso no se podía hacer porque en México no existían tantas variedades de leguminosas como en Europa del Norte, y la posibilidad de su adaptación en las condiciones en que se realizaba la agricultura en amplias regiones de México era limitada (Gutiérrez, 2017, p. 337). A lo 
anterior se agregaría que las alternativas de leguminosas existentes en el país, el frijol y el garbanzo, fueron subestimadas por su baja aportación relativa de nitrógeno.4 En suma, estas alternativas tuvieron sus límites en las condiciones agrícolas y ecológicas mexicanas, productivas y sociales de la agricultura de subsistencia.

Por otro lado, la fertilización química era la base de los modelos planteados para regiones amplias. Según se advierte, los científicos de la OEE se inclinaron por ese tipo de fertilización debido a que facilitaba el tránsito de la milpa (maíz intercalado con otros cultivos, calabaza, por ejemplo) al monocultivo. Para ello, recomendaban cultivar mayores poblaciones de plantas mejoradas de maíz por hectárea, y poner a su disposición fórmulas adecuadas de nitrógeno, fósforo y potasio. Esto puede notarse en publicaciones de científicos de la OEE en las que se observan los siguientes temas: 1) la relación entre cantidad de fertilizante y población de plantas por hectárea (densidad de población), 2) la efectividad de los fertilizantes con relación a los climas, suelos, disponibilidad de agua, 3) métodos de labranza para aumentar la eficiencia de los fertilizantes, 4) mejoramiento y conservación del suelo (Jiménez y Sánchez, 1959, pp. 13-36). En experimentos realizados entre 1955 y 1962 hubo una clara tendencia al incremento en la cantidad de nitrógeno aplicado por hectárea; se partió desde 60, 80, 100, 120, hasta llegar a 150 kilos. Asimismo, esa progresión tenía una relación directa con la densidad de plantas: 35,000, 40,000 y hasta 50,000. En las conclusiones, los científicos establecieron que solo la última combinación 150-50-00 (150 kilos de nitrógeno, 50 de potasio y 0 de fósforo) producía rendimientos por arriba de las 6 toneladas por hectárea; es decir, los mayores rendimientos solo eran posibles si se utilizaban altas dosis de fertilizantes (Bojórquez, 1955, p. 21). Una densidad de plantas por debajo de las 40.000 plantas hacía incosteable el uso de fertilizantes, por lo que el uso de variedades mejoradas se consideraba necesario. Sin embargo, un mayor número de plantas solo era posible con mejores suelos y agua suficiente: de 2 a 5 riegos durante el ciclo completo. En caso de ser agricultura de temporal, la cantidad de humedad necesaria solo se alcanzaba si el promedio de precipitaciones alcanzaba los $800 \mathrm{~mm}$, lo que limitaba el espacio geográfico adecuado para el uso de fertilizantes, pues en México las sequías y la falta de humedad son fenómenos recurrentes en el norte y centro del país (Bojórquez, 1955, p. 21).

Una de las principales dificultades para la difusión de los fertilizantes químicos a nivel nacional fue la disponibilidad de agua, puesto que en los años cuarenta y cincuenta las sequías fueron un fenómeno recurrente: sucedieron en 1943, 1945, 1947, 1949-1954 y 1957 (Gutiérrez, 2017). En ese contexto medioambiental, la irrigación fue un elemento nodal en los experimentos de la OEE, junto con los análisis químicos, las técnicas de cultivo y la elaboración de fórmulas fertilizantes. Al respecto de los primeros, los estudios en cultivos bajo irrigación se enfocaron en detectar los cambios en el $\mathrm{pH}$-alcalinidad, salinidadcon el objetivo de idear estrategias químicas para su resolución. ${ }^{5}$ Problemas de alcalinidad o de acidez impedían las reacciones químicas que liberaban el nitrógeno en el suelo (Yáñez-Pérez, 1957, pp. 197-229). En suma, las ciencias del suelo debían generar conocimientos para hacer más eficiente el uso de altas dosis de fertilizantes químicos. Dichos nutrientes provendrían de una industria que recibió un fuerte impulso del gobierno mexicano desde los últimos años de la década de 1940.

\section{LA FORMACIÓN DE UNA INDUSTRIA DE FERTILIZANTES QUÍMICOS EN MÉXICO}

La agricultura intensiva basada en el monocultivo tuvo en el proceso Haber Bosch -que aprovechaba el nitrógeno atmosférico para producir fertilizantes- una de sus piezas fundamentales. Para 1913 la empresa alemana Badische Anilin-\&Soda-Fabrik ya operaba la primera fábrica de amoniaco (Rueda, 1991, p. 66). Unos años después, en la década de 1930, esa empresa tenía presencia en México. Un ingeniero del Departamento de Agricultura de la Secretaría de Fomento -Andrés Macías- y el gobierno del estado de Jalisco tenían un convenio con Anilinas de México para probar fertilizantes en cultivos comerciales: caña de azúcar, cacahuate y trigo (Gracia, 1998, pp. 176-178). 
A pesar del avance de los abonos minerales y químicos, la apuesta de la política gubernamental en los años treinta era por la explotación sistemática de guanos con alto contenido de nitrógeno, como el de murciélago. En 1943, con la instauración de la paraestatal Guanos y Fertilizantes de México (GUANOMEX), se planearon proyectos para explotar masivamente el guano de aves marinas en las islas del Pacífico, como lo habían hecho durante décadas los peruanos, los cuales resultaron un fracaso (Cushman, 2013, pp. 284-286). Las escasas fuentes de fertilizantes orgánicos con alto contenido nutricio y una demanda creciente incidieron en que el gobierno federal volteara hacia los subproductos de la industria minera. Una opción fue fomentar la producción de amoniaco anhidro - un residuo de la industria del coque ubicada en el municipio de San Juan de Sabinas, en el estado de Coahuila-, aunque su potencial fue limitado. En lo que se refiere al fósforo, GUANOMEX estableció en 1947 la primera planta de superfosfato en San Luis Potosí, que empleaba como insumos roca fosfatada importada de los Estados Unidos y ácido sulfúrico producido en los yacimientos de azufre ubicados en Cerritos, en esa misma entidad. La capacidad instalada de la planta era de 50.000 toneladas de sulfato de superfosfato simple y 5.000 toneladas para mezclas (Gracia, 1998, p. 99).

No obstante, la alternativa que se impuso fue la petroquímica. En 1938 el petróleo fue nacionalizado por el gobierno mexicano; se estableció la empresa paraestatal Petróleos Mexicanos (PEMEX) y se inició una política para impulsar la demanda y el consumo de sus derivados, así como del gas natural. En este escenario, en 1951 inició sus operaciones la planta de Cuautitlán, que produciría amoniaco anhidro, ácido sulfúrico y sulfato de amonio a partir del gas natural. Su capacidad instalada era de 150.000 toneladas de sulfato de amonio, 22.000 de amoniaco anhidro y 130.000 de ácido sulfúrico. La construcción de Cuautitlán, con tecnología de punta para la época, fue resultado del financiamiento del Export-Import Bank (Eximbank), pero también de la aplicación de nuevos procesos tecnológicos generados en empresas norteamericanas como Chemico (sulfato amonio) o Monsanto (ácido sulfúrico), y de la instalación en territorio nacional de los primeros gasoductos que iban desde los centros de producción en el sureste hacia la capital del país y su parque industrial (De León, 2009, pp. 20 y 29). ${ }^{6}$

Con la petroquímica imponiéndose en la industria de fertilizantes, dos tendencias se observan en los años cincuenta y sesenta. La primera es que capital público y privado participaron en su expansión, en procura de disminuir los costos de transporte y localizar las actividades de acuerdo con los espacios de demanda. Bajo esta lógica es que se establecieron diversas plantas, como Industrias Químicas (Zacapu, Michoacán, fines de los cincuenta), Fertilizantes del Bajío (establecida en 1964), Coatzacoalcos y Minatitlán (1962, GUANOMEX, en Veracruz), Torreón (1966, GUANOMEX, Coahuila), Camargo (1967, GUANOMEX, Chihuahua) y Guadalajara (Jalisco, 1969, GUANOMEX) (Guanos y Fertilizantes, 1968, pp. 20-38). Una segunda tendencia que se advierte es un proceso de centralización estatal, notorio en la incorporación a GUANOMEX de las plantas del Bajío, Monclova, Coatzacoalcos y Minatitlán en 1964. Al lado de la centralización, en los años sesenta PEMEX impulsó la expansión de la industria petroquímica mexicana a través de la integración -vía redes de oleoductos- de la producción de gas de los yacimientos del istmo de Tehuantepec y de los principales centros urbanos e industriales del país (Guanos y Fertilizantes, 1968, pp. 20-38; Martínez, 1968, pp. 58-64; De León, 2009, p. 29). En ese contexto GUANOMEX realizó avances en los siguientes temas: 1) un proceso de sustitución de importaciones respecto de la producción de insumos básicos para la elaboración de fertilizantes, como el ácido sulfúrico, ácido nítrico, ácido fosfórico y amoniaco, 2) la producción de amoníaco anhidro en las plantas del Istmo, Cuautitlán, Salamanca, 3 ) producción en los años sesenta de fertilizantes con mayor porcentaje de nitrógeno que el sulfato de amonio (22\%), como el nitrato de amonio (34\%), urea (46\%) y amoniaco anhidro (82 \%), 4) el incremento en la producción de fertilizantes en $228 \%$ durante el periodo 1958-1968 (según las autoridades de GUANOMEX, de 428.000 toneladas a 1.404.628, sin especificar qué clase de fertilizantes) (Guanos y Fertilizantes, 1968, pp. 20-38; Martínez, 1968, p. 65).

Así, mediante la labor de innovación de la OEE y el establecimiento de una industria nacional, la difusión de fertilizantes sería el siguiente paso, uno que llevaría a la agricultura del atraso a la modernidad. 


\section{LA Difusión De FERTILIZANTES QUímicos EN EL OCCIDENTE De MÉXICo}

En la década de 1940 el auge en la producción agrícola repercutió en la necesidad de una mayor cantidad de nutrientes. ¿Cómo se solucionaba el problema de la renovación de nutrientes en los suelos agrícolas en el occidente de México? En Irapuato y León, en el estado de Guanajuato, por ejemplo, los agricultores utilizaban desperdicios orgánicos de los basureros públicos, así como aguas negras. ${ }^{7}$ Además de las opciones anteriores, la aplicación de estiércol vacuno era práctica difundida, como lo confirman dos informes de funcionarios de la misma entidad. En 1949, el ingeniero Luis Alonso Trejo señalaba que "comúnmente se utiliza el empleo de estiércol con lo que se da determinados elementos al suelo, entre ellos principalmente el nitrógeno". Tres años después, el ingeniero Benito Mejía aseguraba que "el estiércol de res era el más utilizado por ser el más barato". ${ }^{8}$

Sin embargo, dos elementos incidieron en que se planteara el cambio del estiércol hacia los fertilizantes. Por un lado, la fiebre aftosa, epizootia que diezmó a la población de ganado vacuno en Guanajuato, Michoacán y Jalisco -entre 500.000 y un millón de cabezas-. Según testimonios de la época, en los campos de cultivo o en barbecho se notaba la ausencia de los vacunos, que mientras devoraban los restos de la cosecha depositaban su estiércol. ${ }^{9}$ El segundo elemento es que en el gobierno federal y en la OEE depositaron su confianza en los fertilizantes químicos para incrementar la producción, por lo que el uso de abonos orgánicos se subestimó por su bajo contenido relativo de nitrógeno, más aún en los años sesenta, cuando en México se comenzaron a producir fertilizantes con mayor con mayor contenido de nitrógeno, caso del nitrato de amonio, la urea o el amoniaco anhidro (Martínez, 1968, pp. 20-38; Mejía, 1956, p. 65). Lo ideal, a decir de agentes de la SAG como Trejo, era emplear fuentes más ricas en nitrógeno, caso de los químicos, mientras el estiércol y los desperdicios urbanos serían usados solo como complementos y mejoradores para engrosar el suelo. ${ }^{10}$

Bajo ese ideal, diversas agencias gubernamentales, caso de la Comisión Nacional del Maíz, GUANOMEX, la Secretaría de Agricultura y Ganadería o la Secretaría de Economía, iniciaron planes para difundir de manera masiva fertilizantes químicos en la agricultura maicera del país. Entre 1940 y 1950 la producción de maíz en el país se había incrementado en más de dos millones de toneladas, a una tasa de $10 \%$ anual, aunque se pensaba que el reparto agrario había sido la principal causa. Para mantener ese crecimiento, o incluso aumentarlo, los funcionarios del gobierno federal y el personal científico de la OEE pensaban que había llegado el momento de la tecnología: semillas mejoradas, fertilizantes, técnicas culturales mecanizadas, pesticidas (Stakman et al., 1967, pp. 3-6).

¿Cómo se difundieron los fertilizantes y las técnicas de conservación de suelos en los campos maiceros del occidente de México? Las fuentes localizadas dan cuenta de dos proyectos de política pública: por un lado, el de la Comisión del Tepalcatepec en Michoacán, que tuvo dos características: a) involucró no solo al maíz, sino a otros cultivos, b) fomentó la producción maicera para incrementar el consumo local o familiar; por otro, la construcción de un plan de tecnificación de la agricultura maicera en el estado de Jalisco para abastecer centros urbanos -Guadalajara y México- y la demanda ganadera e industrial.

En cuanto al primer proyecto, en Michoacán las políticas públicas para la difusión de fertilizantes estuvieron bajo la dirección de la Comisión del Tepalcatepec, liderada por su vocal ejecutivo, el expresidente Lázaro Cárdenas. A partir de su establecimiento en 1949, la Comisión se encargó de tecnificar la agricultura mediante la aplicación de técnicas de irrigación y la difusión de innovaciones agronómicas (Pérez, 2018, p. 130). En el caso de los suelos agrícolas, los ingenieros de la Comisión realizarían labores de conservación de suelos y difusión de fertilizantes, así como capacitación a los agricultores para que, en adelante, ellos pudieran efectuar tales tareas por sí mismos. ${ }^{11}$ Lo anterior se llevaría a cabo en dos regiones: los valles tropicales de Apatzingán y Nueva Italia, y un área montañosa con valles templados en el centro y norte de Michoacán.

Según los informes del ingeniero Félix Ramos Padilla, entre 1956 y 1960 se llevaron a cabo en los valles tropicales mencionados trabajos de nivelación, arado en contorno, trazo de canales de riego y drenaje, y 
recomendación de fórmulas fertilizantes para propiedades privadas de entre 20 y 50 hectáreas, así como para unidades ejidales de entre 4 y 6 hectáreas, en cultivos como algodón, melón, arroz o maíz. Por lo que respecta a los propietarios privados, los testimonios de Ramos Padilla indican que ellos eran los que pedían las labores de conservación de suelos, así como la asistencia técnica para utilizar fertilizantes. Lo anterior muestra también que los agricultores privados tenían cierta familiaridad con el uso de fertilizantes, así como con métodos motorizados de cultivo. ${ }^{12}$

En el caso de las unidades ejidales la situación era distinta. Al respecto, cabe explicar aquí que desde el período presidencial de Lázaro Cárdenas el gobierno federal había expropiado tierras para dividirlas y dotar a campesinos para su explotación colectiva en los valles de Apatzingán y Nueva Italia. De hecho, en esa región el modelo ejidal de posesión y explotación colectiva de la tierra tuvo algún éxito, si bien esto se consiguió mediante un esquema de crédito gubernamental que terminaba por controlar el tipo de cultivo, el calendario agrícola y la comercialización de los productos. Además, la tecnificación también contemplaba un uso racional del suelo y el agua, lo que implicaba que los cultivos más rentables-que no el maíz- dominarían la geografía agrícola diseñada por los ingenieros de la Comisión, y que sobre ellos se aplicarían las innovaciones contempladas dentro de los programas federales de modernización agrícola. ${ }^{13}$

Según el informe del ingeniero Padilla, los ejidatarios no solo no pedían asistencia técnica, incluso se resistían a realizar las labores de conservación del suelo -que además eran mecanizadas-, o aplicar fertilizantes, debido a su alto costo. Pero, además, los ejidatarios se resistían también porque los fertilizantes se utilizaban en altas dosis y sus resultados no siempre eran los esperados. A pesar de lo anterior, y ante las quejas de Padilla, el Comité Agrícola del sistema de riego del río Cupatitzio determinó en 1958 que, en adelante, quienes "no hicieran los trabajos marcados de conservación de suelos, se les cortaba el suministro de agua y las agencias de los Bancos Ejidales de la región no darían crédito a los interesados”. ${ }^{14}$ Ante tal situación, los ejidatarios no tuvieron más remedio que aceptar y realizar las labores de conservación y aplicar los esquemas de fertilización; todo ello mediante los créditos estatales.

En el centro y norte de Michoacán, por su parte, la agricultura maicera se realizaba o bien en las laderas de los cerros, o bien en pequeños valles, en unidades productivas comunales o ejidales. El problema para los ingenieros de la Comisión era que los métodos habían sido probados en campos o estaciones experimentales, en terrenos nivelados, con irrigación o riesgos de auxilio, no en agricultura de temporal. En el caso del arado en contorno, como medida para evitar la erosión, la dificultad consistía en cómo introducir maquinaria en la agricultura de ladera, con pendientes de $20^{\circ}$ o más. Por esas razones, en poblados serranos como Chichota, Carapan o Cherán, la mayoría de las comunidades ejidales no cooperaron con los ingenieros, ni con los pasantes de la Escuela Vocacional de Agrobiología de la Universidad Michoacana, quienes trabajaban en cooperación para la difusión de las nuevas técnicas e insumos agrícolas ${ }^{15}$.

Por otro lado, las recomendaciones de fórmulas fertilizantes no eran tampoco las adecuadas. En Michoacán, la Sociedad de Crédito Local de la localidad de Tingambato se quejó ante el gobernador del estado de que los fertilizantes que les había recomendado el ingeniero del Banco Nacional de Crédito Agrícola "no respondieron (a las expectativas)... y aparte de ser muy caros, ya le decimos que no nos beneficiaron y sí nos endrogaron (endeudaron)" ${ }^{16}$ Los problemas de la asistencia técnica se advierten más claros en un testimonio de la población de Nahuatzen, que refiere los estragos de las recomendaciones de fertilizante hechas por el ingeniero del BNCA: "la planta no creció ni ocho pulgadas y no dio nada de producto". Estas contrariedades se debían a la ausencia de un adecuado análisis de suelos, como reconocían los propios ingenieros, con los resultados ya comentados. ${ }^{17}$ 
MAPA 2

Ubicación en el estado de Michoacán de los espacios en los que se difundieron fertilizantes de GUANOMEX

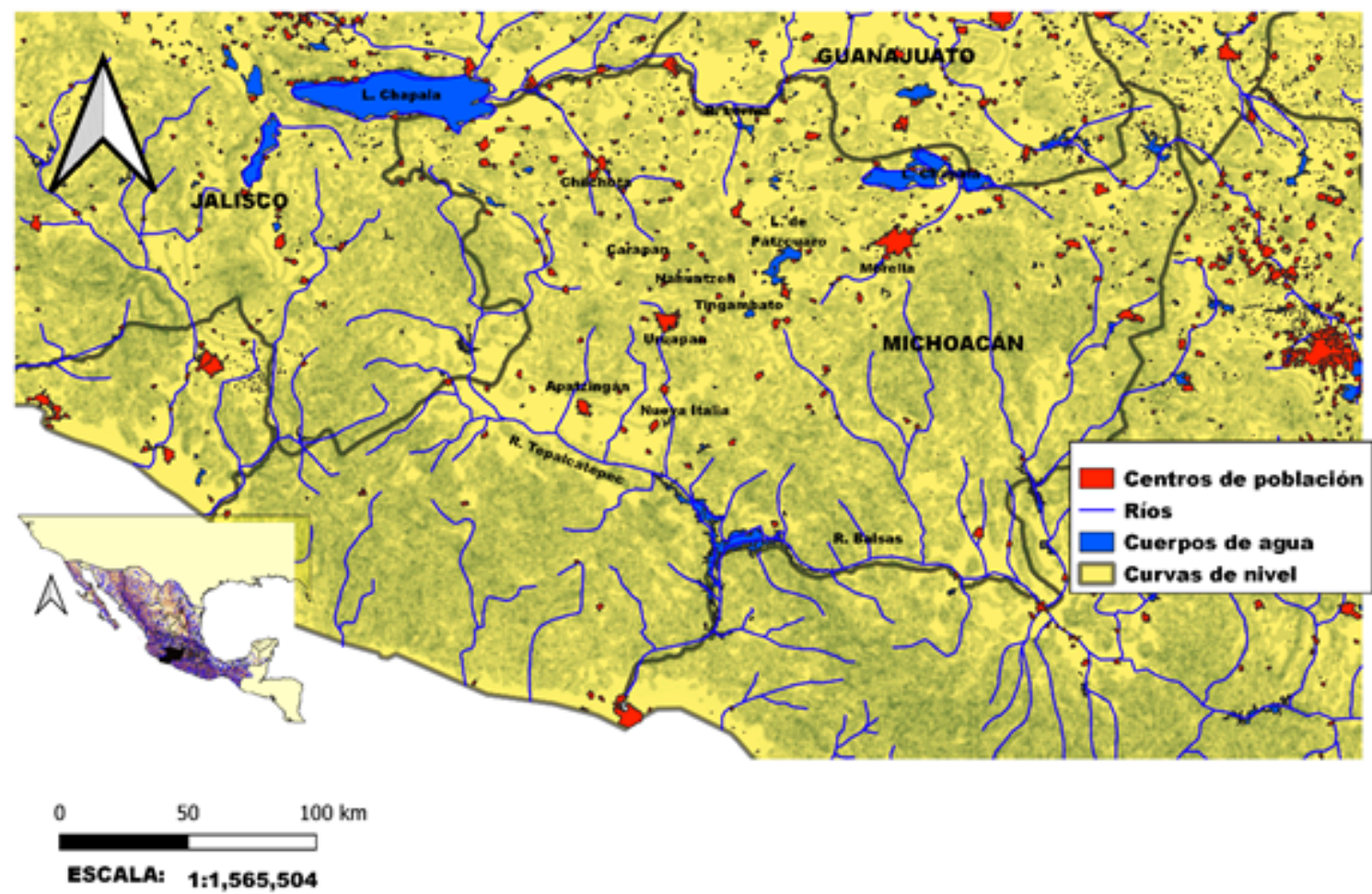

Fuente: Elaboración propia.

Además de las recomendaciones fallidas, otro problema era la calidad de los fertilizantes ofrecidos por GUANOMEX, menor que la de los ofertados por empresas privadas. Desde los años treinta, Casa Beick y Bayer vendían fertilizantes importados de Alemania, sobre todo en ciudades importantes de Michoacán, caso de Uruapan o Morelia. En 1952, agricultores de esa última ciudad se quejaban ante el gobernador Dámaso Cárdenas sobre la "pésima calidad de los fertilizantes de GUANOMEX y los excelentes resultados en maíz de los que vendía la casa Beick". ${ }^{18}$ Aunado a lo anterior, la intervención de GUANOMEX en el mercado generaba escasez, consecuencia de su limitada capacidad de producción en los años cincuenta. ${ }^{19}$

El segundo patrón observado es el de los grandes planes de tecnificación de la agricultura maicera. Si ya la escasez de humedad era un problema, la sequía de 1957, la más intensa en lo que iba del siglo, disminuyó las cosechas a nivel nacional, por lo que se importaron 1,6 millones de toneladas de maíz (un $36.5 \%$ de la producción de 1956). Al año siguiente, el ingeniero David Ibarra, gerente de ventas de GUANOMEX, planteó la solución para terminar con el problema de las importaciones: incrementar la producción utilizando fertilizantes químicos. Sin embargo, la solución tenía dos inconvenientes. El primero, una producción nacional insuficiente. El segundo, que aun con una producción suficiente la humedad era necesaria para que alcanzaran su máximo potencial. Por lo anterior, y ante la necesidad de dar una "batalla del maíz", Ibarra dirigía la atención hacia 1,5 millones de hectáreas de temporal en el centro del país con precipitaciones pluviales de entre 800 y $1.200 \mathrm{~mm}$ anuales y 166.000 hectáreas de riego cultivadas con maíz, que, decía, había en México en ese año (Ibarra, 1958, pp. 13-20). 
El ingeniero señalaba que el plan comenzaría "en aquellas zonas donde la confianza y conocimiento de los fertilizantes están más adelantados, y señalamos concretamente al estado de Jalisco, que tiene un área de maíz fertilizable con éxito de unas 600,000 has, de las cuales ha sido posible fertilizar solo 100,000”; esas hectáreas, por cierto, tenían un relieve poco pronunciado. En Jalisco, por tanto, sería la primera batalla del maíz de GUANOMEX, con un programa de fertilización de 200.000 hectáreas anuales (Ibarra, 1958). El Plan Jalisco inició en 1958 y contó con la suerte de que la sequía terminó justo en ese año. Así, para principios de los años sesenta, el Plan Jalisco contaba con créditos, semillas mejoradas y un sistema de cultivo, el zapopano, que buscaba retener la materia orgánica y la humedad para resistir la escasez temporal de humedad ("Tecnificarán 120,000 has de maíz utilizando el 'sistema zapopano'”, jueves 1 de julio de 1965, p. 3A).

Para fertilizar 1,65 millones de hectáreas, Ibarra calculaba que se requerirían 82.500 toneladas de nitrógeno, con un coeficiente por hectárea de 50 kilos, 10 por debajo de la recomendación de Colwell. Esa cantidad, sin embargo, implicaba un déficit para la producción nacional de 23.851 toneladas (Tamayo, 1964, p. 128) ${ }^{20}$. Así, un elemento clave del plan era que GUANOMEX incrementara su producción. Esto sucedió en dos momentos: en 1955, y luego un aumento más fuerte en 1962, con el establecimiento de las plantas en Cosoleacaque y Minatitlán en el estado de Veracruz (ver gráfico 1) ${ }^{21}$. En ese último año, la producción de nitrógeno en GUANOMEX aumentó en 68.346 toneladas (el mayor incremento en un año para el periodo 1950-1968), lo que se debió a que se comenzaron a producir fertilizantes con mayor porcentaje de ese elemento químico: mientras el sulfato de amonio $(21 \% \mathrm{de} N)$ tuvo un aumento de 4641 toneladas o $3 \%$, el nitrato de amonio ( $34 \%$ de N) aumentó 52.984 toneladas o $75 \%$, y el amoniaco anhidro (82\% de N) 61.668 toneladas o $161 \%$. En 1963, la paraestatal inició la producción de urea ( $46 \%$ de N) con 38.578 toneladas, principalmente en la planta situada en el Bajío, en el estado de Guanajuato (Guanos y Fertilizantes, 1968). Ya para 1964 la producción era de 196.631 toneladas de nitrógeno, suficientes fertilizar 3,6 millones de hectáreas, un $72 \%$ de los 5,04 millones de hectáreas con eficiencia termopluviométrica que había en todo el país (Programa Nacional, 1970).

\section{GRÁFICO 1}

cantidad de nitrógeno producido por GUANOMEX, de todas las clases de fertilizantes. En toneladas anuales

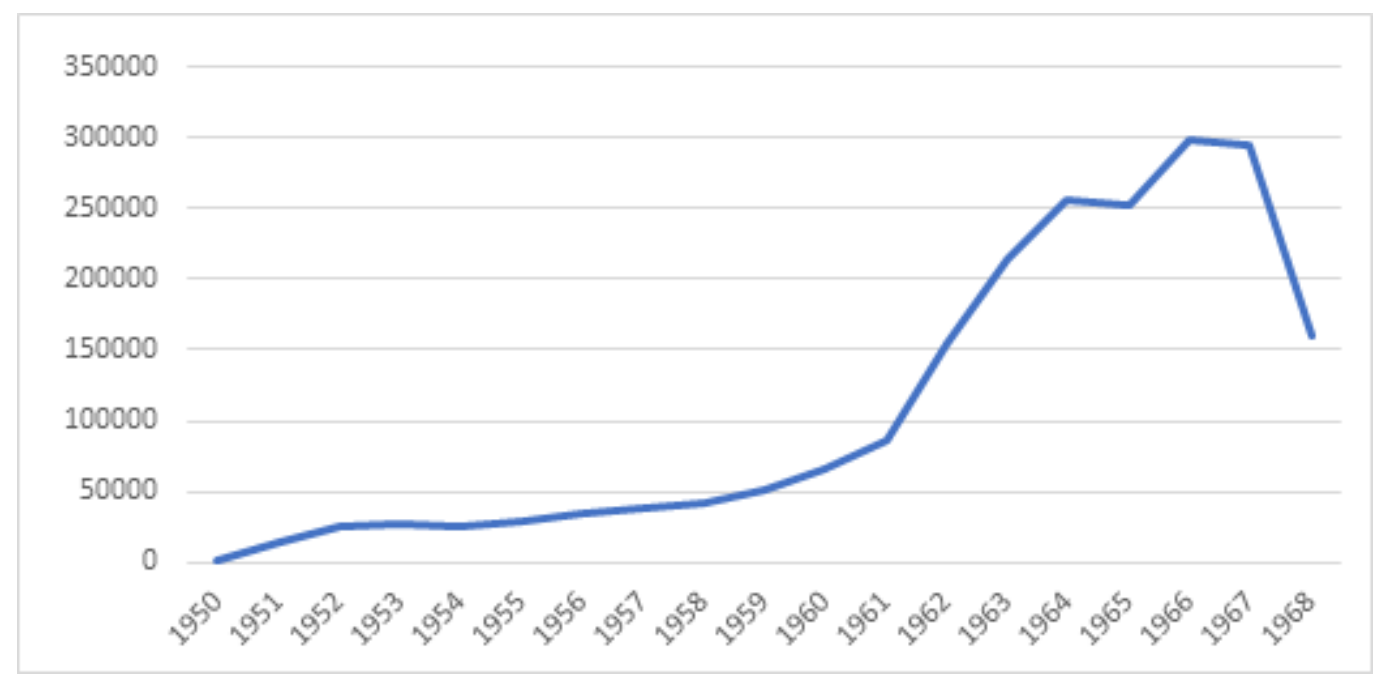

Elaboración propia. Fuentes: de 1950 a 1962 son de Tamayo, 1964, p. 133, tabla XXII, "Producción Nacional de Fertilizantes"; 1962 a 1967 son de Martínez, 1968, p. 70, "cuadro 1, "Producción Nacional de Fertilizantes".

El crecimiento de la producción de GUANOMEX y los factores mencionados tuvieron que ver, en parte, con el Plan Jalisco. Por un lado, desde 1961 los agricultores de esa entidad eran los principales compradores de fertilizante a la paraestatal, con el $17 \%$ del total vendido en el país, porcentaje que se incrementó a $23 \%$ 
en 1963 (Tamayo, 1964). Por otro lado, la demanda de fertilizante acompañó al incremento de la superficie maicera fertilizada en Jalisco, pues, de acuerdo con cifras publicadas en la prensa jalisciense, el número de hectáreas aumentó de 100.000 en 1958 a 155.000 en 1960, a 450.000 en 1963, y a 550.000 en 1964 ("Plan Jalisco", miércoles 20 de marzo de 1963, El Informador, p. 3A).

Sin embargo, esa imagen positiva debe matizarse. Si bien la agricultura maicera jalisciense era la principal compradora de fertilizantes a GUANOMEX, las cantidades adquiridas entre 1961 y 1963 eran suficientes solo para 257.930 hectáreas en 1963 y para 350.087 en 1964, cuando las cantidades fertilizadas habían sido de 450.000 y 500.047 hectáreas respectivamente; es decir, habría un déficit de 192.070 y 149.960 hectáreas (Tamayo, 1964, p. 128). Lo anterior, bajo el supuesto de que todo el fertilizante adquirido fuera aplicado al maíz. Sin embargo, en realidad solo el $87 \%$ se destinaba a ese cereal, lo que aumentaba el déficit a 230.921 y 195.471 hectáreas, situación que empeoraba con la escasez de sulfato de amonio experimentada en el año 1963, como resultado de que la producción se centró en otros fertilizantes con mayor cantidad de nitrógeno (Tamayo, 1964, p. 128). De hecho, en ese año el gobierno del estado de Jalisco y GUANOMEX trataron de que los agricultores emplearan el nitrato de amonio en vez de sulfato, lo que fue problemático debido a que el primero tenía un costo por hectárea $51 \%$ mayor (Guanos y Fertilizantes, 1968). Por lo anterior, el faltante de sulfato de amonio fue cubierto con importaciones de Estados Unidos y Japón ("Habrá fertilizantes para las siembras", jueves 20 de junio de 1963, El informador, p. 7A). De igual manera, y como se advierte en la figura 1, para 1968 la tendencia de la producción de nitrógeno en GUANOMEX estaba declinando, o por lo menos volvió a ser errática.

Hay también otros elementos que cuestionan esa imagen positiva de la difusión de fertilizantes en el Plan Jalisco. Uno de ellos es el costo por hectárea. Si bien es cierto que disminuyó la relación entre el costo del fertilizante utilizado por hectárea tras la apertura de la planta de Cuautitlán, también lo es que la aplicación de abonos químicos implicaba el empleo de técnicas mecanizadas que incrementaban los costos totales a 1.556 pesos en 1963; esto, a decir de la Liga de Comunidades Agrarias y la Federación de Pequeños Propietarios de Jalisco. Tal cifra representaría un $68 \%$ de los ingresos por hectárea si la cosecha obtenida fuera de 2,5 toneladas por similar unidad de superficie; en caso contrario, la situación de los agricultores devenía crítica. El problema era aún más grave, pues las citadas organizaciones planteaban que los costos de producción se incrementaban cada año, y, ante un precio controlado del grano por el gobierno federal, los ingresos se reducían cada vez más (Martínez, 1968, pp. 59-64; Mesa y Alanís, 1951, p. 56; “¡Y el Plan Jalisco?”, miércoles 22 de mayo de 1963, El informador, p. 1A)22. Para vencer a los costos crecientes, en el plano técnico la solución recomendada por los ingenieros fue aumentar los rendimientos mediante la aplicación de fertilizantes con mayor porcentaje de nitrógeno, caso del nitrato y mayor densidad de plantas por hectárea. Sin embargo, esas soluciones tenían varios factores en contra: la persistente mala calidad de los fertilizantes, las limitaciones en la oferta nacional, la falta de adecuación en las fórmulas recomendadas y la deficiente asistencia técnica (Peña-Cabrioles, 2001, p. 52). Además, la idea de aumentar los rendimientos con mayores dosis de fertilizantes encontró un punto de tensión con el propio planteamiento del Plan Jalisco, pues había que ampliar el beneficio de los abonos químicos al mayor número de hectáreas posible, por lo que los técnicos estaban recomendando fórmulas por debajo del coeficiente establecido por Colwell, entre 40 y 50 kilos por hectárea. Resultado de lo anterior fue que se establecieron dos esquemas de fertilización: uno con bajas dosis por hectárea y menores rendimientos, y otro basado en altas dosis de agua y nitrógeno con mayor productividad. (Peña-Cabrioles, 2001, p. 52).

¿Cuáles fueron los resultados de la difusión de fertilizantes en el Occidente de México? Respecto de los casos que nos ocupan, conviene separar el análisis de la década de 1950, atravesada por sequías intensas, y la de 1960. En Guanajuato y Michoacán, la producción de maíz se incrementó en mayor medida en la década de 1960, con tasas de $4 \%$ y $6 \%$, pero fue en Jalisco donde el crecimiento fue mayor con una tasa de 10 $\%$. Ahora bien, en Jalisco la producción con semillas mejoradas tuvo también un incremento importante, con una participación dentro de la producción total de un 18 \% (en Guanajuato un 12 \% y en Michoacán 
apenas un $8 \%$ ) (Gutiérrez, 2017, pp. 502-505). Asimismo, habría que considerar que en Jalisco se habría fertilizado un 49,5\% de las hectáreas sembradas con maíz (305.087 de 706.843) (Tamayo, 1964, p. 128). Lo anterior explica que los rendimientos en Jalisco tuvieron una tendencia de crecimiento en los años sesenta de $4 \%$ anual, mientras en Guanajuato y Michoacán apenas alcanzaron un punto porcentual (Gutiérrez, 2017, pp. 502-505). En suma, las evidencias indican que la difusión de fertilizantes en la agricultura maicera del occidente de México tuvo mayor fuerza en el estado de Jalisco, como resultado del Plan. Ahí, según los testimonios, la fertilización, las semillas mejoradas y técnicas mecanizadas se utilizaron en el cultivo del maíz con el objetivo de aumentar la producción de manera acelerada para satisfacer la demanda urbana.

Sin embargo, en esto se debe considerar que a partir de 1965 la tendencia de incremento de la producción maicera terminó: entre ese año y 1970 decreció a una tasa de $-0.2 \%$ anual (Gutiérrez, 2017, p. 385). Esa caída, al parecer, influyó en una reconsideración sobre los esquemas de tecnificación. Por un lado, en 1965 Reggie Laird -ya para entonces investigador del Colegio de Postgraduados- observó una gran variabilidad en la respuesta a los fertilizantes de los suelos agrícolas ubicados en zonas de eficiencia termopluviométrica. Por lo anterior, Laird estableció una nueva regionalización de las áreas maiceras, basada no solo en las precipitaciones sino también en las características edáficas, el clima, tipos de cultivo y de productor, técnicas de manejo y la disponibilidad de agua: los denominados sistemas de productividad (Laird y Rodríguez, 1965, p. 36). Tres años más tarde, Roberto Núñez, del Instituto Mexicano para la Productividad, recuperó los estudios de Laird y señaló la necesidad de definir tales sistemas bajo un estricto mapeo de suelos, que continuase con la labor de diversas instituciones del gobierno federal y que integrase los trabajos de la FAO. Solo un mapeo de suelos “permitiría una más certera recomendación de fertilizantes y mejoradores, capacidad de uso, prácticas agrícolas para su mejor utilización y conservación” (Núñez, Programación, pp. 3 y 7). Se asumían así los errores que hemos observado por un deficiente conocimiento de los suelos y sus necesidades. Sin embargo, la concepción sobre los suelos agrícolas con énfasis en lo fisicoquímico y en los fertilizantes continuó. Fue hasta los años ochenta y noventa del siglo pasado que la microbiología de suelos comenzaría, apenas, a adquirir importancia. $^{23}$

\section{Conclusiones}

En este artículo se mostró como unas ciencias del suelo que se enfocaban en los fenómenos fisicoquímicos, y subestimaban los microbiológicos, se difundieron en México entre las décadas de 1940 y 1950, de la mano de la labor de innovación de científicos estadounidenses de la OEE.

Con ese enfoque, en la OEE se realizaron investigaciones sobre los suelos mexicanos que detectaron, en lo general, un déficit de nitrógeno. Para subsanarlo, los científicos recomendaron fertilizantes químicos y prácticas de manejo mecanizadas, con el objetivo de incrementar la productividad. En sus experimentos se advirtió el uso de concentraciones cada vez mayores de nitrógeno, así como mayores densidades de plantas por unidad de superficie, que en teoría permitirían solventar los costos crecientes de los fertilizantes. Esta variable de los costos, así como la complejidad de las tareas agrícolas necesarias para el uso de los abonos químicos y las sequías que azotaron el centro y el norte del país entre los años cuarenta y cincuenta del siglo $\mathrm{XX}$, incidieron en que las innovaciones de nutrientes químicos se fueran concentrando en áreas con mejores condiciones agrológicas, hídricas y climáticas.

Por otro lado, en el trabajo se observó cómo la relación entre una creciente demanda de nitrógeno y la expropiación y expansión de una industria petrolera nacional abrió la puerta para el establecimiento de una industria petroquímica de fertilizantes químicos. Con base en esa industria petroquímica, y en las investigaciones de la OEE, el gobierno mexicano impulsó políticas públicas para la difusión de fertilizantes y técnicas de cultivo mecanizadas, a la vez que desestimó alternativas que hubieran podido aliviar suelos fatigados en la agricultura campesina, sobre todo si se hubieran estudiado más para adecuarse a sus necesidades, caso de los abonos verdes. El uso intensivo de fertilizantes, en cambio, permitía, por un 
lado, alimentar la naciente industria paraestatal nacional -GUANOMEX-, y, por otro, constituir planes para incrementar la producción maicera en diversas regiones en México con modelos de intervención homogéneos. En el caso de Michoacán, la difusión de fertilizantes y técnicas de conservación presentó dificultades debido a que, o bien no estaban adecuadas para la agricultura de ladera, o bien el hecho de no contar con análisis de suelos redundó en una deficiente asistencia técnica. Asimismo, hay que mencionar la escasez de lluvias o la presencia de compañías privadas, que representaron también un problema para la paraestatal. No obstante, no se debe soslayar que la difusión de fertilizantes, si bien acusó algunos de los problemas mencionados, contó con la práctica estatal de ejercer coerción sobre los ejidatarios para que los usaran, a cambio de contar con riego para sus cultivos. En pocas palabras, los terrenos de los ejidatarios se convirtieron en laboratorios de extensión para las nuevas tecnologías.

En el caso de Jalisco, si bien las dificultades mencionadas también aparecían, el plan de tecnificación aplicado ahí tuvo mayor éxito, debido a que contaba con extensiones planas y con un promedio anual de precipitaciones adecuado para el cultivo del maíz. Según los datos disponibles, fue en ese estado donde el uso de fertilizantes, semillas mejoradas y técnicas de cultivo mecanizadas tuvieron mayor incidencia en los rendimientos y la producción, lo que influyó para que se convirtiera en uno de los primeros productores a nivel nacional en 1970. Sin embargo, como se advirtió en el trabajo, la producción decayó a partir de 1965, y una de las posibles causas que se manejaron en los círculos técnicos y políticos fue la productividad. Las investigaciones de Laird y Núñez parecen responder a esta preocupación, expresada en la idea de tecnificar espacios ya no sólo con base en el nivel del terreno o en las precipitaciones, sino en tipos de cultivo y de productor, clima, técnicas culturales, y, más aún, en análisis químicos de suelos que incidirían en mejores recomendaciones de fórmulas fertilizantes.

Lo anterior, sin embargo, no significó que el enfoque cambiara. La agronomía heredera de la OEE se pensaba en función de mejoradores de suelos -estiércol, abonos verdes-, pero, sobre todo, en función de altas dosis de fertilizantes para aumentar la productividad. Esto se llevó a la práctica, aunque se supiera que con el tiempo tales prácticas producirían daños en la composición bioquímica y física del suelo y con ello la anhelada productividad decayera. Así, a pesar de las contraindicaciones, entre los años cuarenta y sesenta, un enfoque extractivo del suelo agrícola se difundió, vinculado con una industria petroquímica que experimentó una acelerada expansión luego de la Segunda Guerra Mundial. En cambio, el otro enfoque sobre los suelos agrícolas, biológico y ecológico, que articulaba los fenómenos del suelo con los atmosféricos a escala planetaria, fue desestimado, y tuvo que esperar al fin del siglo para adquirir importancia ante los problemas ambientales que provocaba la agricultura resultado del modelo de la Revolución Verde: contaminación de suelos, aguas y problemas de salud pública en diferentes partes del mundo.

\section{ArCHIVOS}

Archivo General e Histórico del Poder Ejecutivo del Estado de Michoacán (AGHPEM). Archivo General e Histórico del Estado de Guanajuato (AGHEG).

Archivo Histórico del Estado de Jalisco (AHEJ).

Rockefeller Archive Center (RAC).

\section{Periódicos}

El Informador. 


\section{REFERENCIAS}

Ackert, Ll. Jr. (2007). The "Cycle of Life" in Ecology: Sergei Vinogradskii’s Soil Microbiology, 1885-1940". Journal of the History of Biology, 40(109), 109-145.

Bojórquez, J. (1955). Resultados obtenidos con el empleo de fertilizantes en Ciudad Guzmán, Jalisco. Boletín de Guanos y Fertilizantes de México, S.A, (3), 21 y 22.

Brevik, E. C, Fenton T. and Homburg, J. A. (2016). Historical highlights in American soil science-Prehistory to the 1970s, Catena, (146), 111-127.

Cleaver, H. (March 1972). The Contradictions of the Green Revolution. The American Economic Review, 62(2), 176-186.

Colwell, W.F. (1947). Fertilizante Comercial conteniendo nitrógeno y fósforo para aumentar los rendimientos del maiz (Folleto). Chapingo: Oficina de Estudios Especiales.

Comino, J. R. y Senciales González, J.M. (2013). La Edafogeografía: la quinta rama olvidada de la geografía física. Cuadernos Geográficos, 52(1), 6-28.

Cotter, J. E. (1994). Before the green revolution: Agricultural science policy in Mexico, 1920-1950, (Tesis doctoral inédita), Universidad de California, California, Estados Unidos.

Covarrubias, R. y Rodríguez, A. (invierno 1956-1957). Primera siembra experimental de maíz en "El Cayal", Campeche. Agricultura Técnica en México, (3), 12-13.

Cruz Reynoso, A. (1989). Las alternativas para aumentar la producción en el ejido Trejos, Municipio de Ixtlahuaca del Río. (Tesis de licenciatura inédita), Universidad de Guadalajara, Facultad de Agronomía, Guadalajara, Jalisco.

Cushman, G. T. (2013). Guano and the Opening of the Pacific World, New York: Cambridge University Press.

De León Vázquez, E. (2009). La Producción de Fertilizante a partir de Gas Natural, (Tesis de licenciatura, inédita), Instituto Politécnico Nacional, Escuela Superior de Ingeniería Química e Industrias Extractivas, México D.F., México.

Dworkin, M. (2012). Sergei Winogradsky: a founder of modern microbiology and the first microbial ecologist. Microbial Review, (36), 364-379.

Fernández, R y Laird, R.J. (1957). Riegue el maíz espigando. Agricultura Técnica en México, (4), 46-47.

Fitzgerald, D. (Summer, 1996). Blinded by Technology: American Agriculture in the Soviet Union, 1928-1932. Agricultural History, 70 (3), 459-486.

Garrabou Segura, Ramón, (19-23 de abril, 1993), Revolución o revoluciones agrarias en el siglo XIX: su difusión en el mundo mediterráneo, presentada en Agriculturas mediterráneas y mundo campesino: cambios históricos y retos actuales: actas de las Jornadas de Historia Agraria, Almería, España.

Grabowski, R, Sánchez O. (June 1987). Technological Change in Mexican Agriculture: 1950-1979. Social and Economic Studies, 36(2), 187-205.

Gracia Fadrique, J. (1988). Estado y fertilizantes 1760-1985, México: Fondo de Cultura Económica.

Guanos y Fertilizantes de México. (1955). Editorial. Boletín de Guanos y Fertilizantes de México, S.A., .(1), 1.

Guanos y Fertilizantes de México (1968), Guanos y Fertilizantes de México,México, D.F.: Guanos y Fertilizantes de México.

Gutiérrez Núñez N. L. (2017).Cambio agrario y revolución verde. Dilemas cientificos, politicosy agrarios en la agricultura mexicana del maiz, 1920-1970 (Tesis doctoral, inédita). El Colegio de México, Centro de Estudios Históricos, México, D.F., México.

Harwood, J. (2012). Europe's Green Revolution and Others Since. The rise and fall of peasant-friendly plant breeding. Estados Unidos: Routledge.

Heckman, J. R. (2013). Soil fertility management a century ago. Farmers of Forty Centuries. Sustaintability, (5), 2796-2801.

Hernández Santiesteban, Y, Alfaro Alfaro, E., Mederos Medros, D., Rivas Figeredo, E. (2009). Las coberturas vivas en sistemas de cultivos agrícolas, Temas de ciencia y tecnología, 13 (39), 7-16. 
Ibarra, D. (1958). Los fertilizantes y la batalla del maíz. Boletin de Guanos y Fertilizantes, (15), 13-20.

Jiménez, M y N. Sánchez Durón, (1958-1959). “Experimentos con maíz en el valle de Yaqui”. Agricultura Técnica en México, (7), 13 y 36.

Kay, L. (1993). Molecular Vision of Life. The Rockefeller Foundation and the Rise of the New Biology, New York: Oxford University Press.

Kellogg, Ch. (1957). We Seek, We Learn, Soil. (pp. 1-11), The Yearbook of Agriculture 1957, Washington, D.C: US Department of Agriculture.

Revista Tierra. (1950). Editorial. Tierra, 16 (2), 117.

Laird, R.J. y Rodríguez H. (1965). Fertilización de maiz de temporal en regiones de Guanajuato, Michoacán y Jalisco. México, D.F: Secretaría de Agricultura y Ganadería.

Legros, J. P. (2011). A l'aube de la Science du Sol. Conférence 4166 presentée au Seance du Lundi. Académie des Sciences et Lettres de Montpellier, Montpellier, France.

Lorek, T. (2019). Developing Paradise: Agricultural Science in the Conflicted Landscapes of Colombia's Cauca Valley, 1927-1967. (Tesis doctoral inédita). Universidad de Yale, New Hampton, Estados Unidos.

Martínez W.R. (1968). La oferta y demanda de los fertilizantes en México. (Tesis de Licenciatura). Universidad Nacional Autónoma de México, Facultad de Economía, México D.F., México.

Mattchet, K. (2002). Untold Innovation: Scientific Practice and Corn Improvement in Mexico, 1935-1965. (Tesis doctoral inédita). Universidad de Minnesota, Minneapolis, Estados Unidos.

Mejía Gutiérrez, J. (1965). La Industria de Fertilizantes en México. (Tesis de licenciatura, inédita). Universidad Nacional Autónoma de México, Facultad de Economía, México D.F., México.

Mesa Andraca, M y Alanís Patiño E. (enero-marzo 1951). La agricultura en México. Problemas agrícolas e industriales de México, 3(1), 23-183.

Neve, J., Osler, R.D. (invierno 1956-1957). Nueva promesa para el noroeste. Agricultura Técnica en México, 3(16), 16 y 17.

Núñez Escobar, R. (27 de julio 1968). Programación de la investigación en reconocimiento de suelos y uso de fertilizantes $y$ mejoradores. Trabajo presentado en la Reunión Nacional de Ciencia y Tecnología en la Reforma Agraria, celebrada en el Centro Interamericano de Estudios de Seguridad Social, San José, Costa Rica.

Paull, J. (2006). Permanent Agriculture Precursor to Organic Farming. Journal of Byo-Dynamics Tasmania, (83), 19-21.

Peña, R. (1958). Experimento factorial. Conducido con maíz en Hidalgo, Michoacán, para investigar cuatro fórmulas fertilizantes y tres densidades de siembra. Boletin de Guanos y Fertilizantes de México, 2(14), 4-6.

Peña-Cabrioles J.J., Grageda-Cabrera O. A., Vera-Núñez, J.A. (octubre 2001). Manejo de los fertilizantes nitrogenados en México: uso de las técnicas isotópicas. Terra, (20), 51-56.

Peregrina, R., Toro J., Reggie Laird J. (1955). El Hubam como abono verde. Agricultura Técnica en México, (3), 5.

Pérez Ortiz, L. A. (2018). Fausto en el trópico seco. El distrito de riego de la Tierra Caliente del Tepalcatepec, 1927-2011, (Tesis doctorado, inédita), El Colegio de Michoacán, Centro de Estudios Rurales, Zamora, México.

Perkins, J. (1997). Geopolitics and the Green Revolution, Wheat, Genes, and the Cold War, New York: Oxford University Press.

Perry, J.P., Gil J., Martínez Lima, J. (invierno 1958-1959). Fertilizantes para Maíz en Campeche. Agricultura Técnica en México, (7), 3 y 40.

Perry, J.P., Rachie O., Gil J. (verano 1955). “El arado de barra con dientes rígidos” en Agricultura Técnica, (2), 20 y 21.

Phillips, S. T. (1970). This Land, This Nation. Conservation, Rural America, and the New Deal, New York: Cambridge University Press, 2007.

Secretaría de Agricultura y Ganadería. (1970). Programa Nacional de Fertilización 1967-1970. México, D.F.: Secretaría de Agricultura y Ganadería.

Rueda Peiro, I. (1991). La industria de losfertilizantes en México. México: Universidad Nacional Autónoma de México. 
Stakman, E.C., Bradfield, R., Mangelsdorf, P. (1967). Campaigns against hunger. Cambridge: Harvard University Press.

Stoll, S. (2003). Larding the Lean Earth. Soil and Society in Nineteenth Century. USA: Hill and Wang.

Tamayo, J. (1964). El Problema Fundamental de la Agricultura Mexicana. México: Instituto Mexicano de Investigaciones Económicas.

The Rockefeller Foundation. (1948). The Rockefeller Foundation Annual Report 1947, Nueva York: The Rockefeller Foundation.

Yáñez-Pérez, L. (1957). Mecanización de la agricultura mexicana. México, D.F: Instituto Mexicano de Investigaciones Económicas.

Willis, R.J. (2007). The History of Allelopahy. Dordrecht: Springer.

Worster, D. (2004). Dust Bowl. The Southern Plains in the 1930s. New York: Oxford University Press.

Wright A. (2012). Downslope and North. How Soil Degradation and Synthetic Pesticides Drove the Trajectory of Mexican Agriculture through the Twentieth Century. In Christopher Boyer editor. A Land Between Waters. Environmental Histories of Modern Mexico (pp. 22-50), Arizona, The University of Arizona Press.

Zanden J.L. (1991). The first Green Revolution: the growth of production and productivity in European Agriculture, 1870-1914. Economic History Review, 44 (2), 215-219.

\section{FuENTES EN INTERNET:}

Santos, A. T. (2016). Contenido total de nutrimentos en algunos estiércoles en México (exclusivo en línea). Sistema de Agronegocios Agricolas. Recuperado de http://www.sagarpa.gob.mx/desarrollorural/Documents/fichasaapt/ utilizaci\%F3n\%20de\%20esti\%E9rcoles.pdf.

\section{Notas}

1 En la historiografía sobre la Revolución Verde se han abierto nuevos campos de estudio. Entre los más notables están los que se han preocupado por revisar a la Revolución Verde como un proceso de larga duración, que habría tenido sus raíces en la segunda mitad del siglo XIX y en particular con la Segunda Revolución Industrial (Zanden, 1991, pp. 215-219). Desde otra vertiente, las investigaciones han revisado las tesis de los años setenta que proponían a la Revolución Verde como una imposición imperialista (Cleaver, 1972). A este respecto lo que algunos investigadores han advertido es que hubo intereses comunes entre el país de origen de las tecnologías agropecuarias, Estados Unidos, y los países receptores como México o la India, así como otros que dependían de los objetivos de política interior de esos dos últimos (Perkins, 1997). En la década pasada y la actual, por otro lado, las investigaciones han hecho importantes avances al enfocar a la circulación de conocimientos y tecnologías, conducida por diversos agentes, locales y trasnacionales (Lorek, 2019). Asimismo, se observan estudios que exploran la relación entre el avance de la Revolución Verde y el de la agroindustria, así como su vinculación con un cambio en la dieta en Occidente hacia un alto consumo de proteínas, grasas y azúcares (Gutiérrez, 2017).

2 Según el doctor John Larsen, microbiólogo vegetal y de suelos del Instituto de Investigaciones en Ecosistemas y Sustentabilidad de la UNAM, en el norte de Europa la microbiología de suelos recibió un impulso importante en los años sesenta del siglo pasado, aunque su crecimiento más relevante debe ubicarse entre los años ochenta y noventa. Larsen J., comunicación personal, 17 de octubre de 2017.

3 Por tecnologías peasant-friendly, Harwood se refiere a aquellas que son adecuadas para la agricultura campesina, con menos recursos (agrícolas y capital) respecto de la agricultura intensiva capitalista. Estas alternativas tecnológicas más adecuadas a la agricultura campesina (peasant-friendly) se asemejan a lo que observó Jonathan Harwood en el sur de Alemania a fines del siglo XIX (Harwood, 2012, pp. 16-55).

4 Sauer, Carl. February 10, 1941. Comments by Professor Carl Sauer, University of California on Vice-President Wallace's idea that the Foundation should work in Mexico in Public Health, Nutrition, and Agriculture. (Projects-1.1 Series Mexico-323, box 1, folder 2). Rockefeller Archive Center (en Adelante RAC), Nueva York, Estados Unidos.

5 Así lo demuestran los estudios de Luis Yañez-Pérez sobre los suelos mexicanos en los años cincuenta, en los que mapeaba el pH edáfico, así como el grosor y la cantidad de materia orgánica, factores que explicaban la mayor o menor fertilidad. 
6 En la posguerra, a partir del invento del catalizador para elaborar amoníaco con sulfuros del gas natural como materia prima, estos devinieron en el principal insumo de esa industria. Al 2009, el 77 \% de la producción mundial de amoníaco empleaba gas natural como materia prima.

7 Solicitud de dotación de aguas, poblado la Zahurda, Irapuato Guanajuato. 9 de agosto 1943. Aguas e irrigación, (fondo 3.43, Lugar-Irapuato, expediente 1, fojas 2). Archivo General e Histórico del Estado de Guanajuato (en adelante) AGHEG, Guanajuato, Guanajuato, México. "Comunidades agrarias de Santa Rosa y Plan de Ayala, contrato de concesión de aprovechamiento de aguas negras con la presidencia municipal y el delegado de promoción ejidal, 10 pesos por tandeos de tres días a la semana”. 11 de febrero de 1943. Aguas e irrigación. (fondo 3.43, Lugar-León, expediente 1, fojas 1). AGHEG, Guanajuato, Guanajuato, México. Zubirán, S. 21 de octubre de 1942. Solicitud para que le sea cedida la mitad o tercera parte de la basura de León, para utilizarla en bonificar la tierra del Rancho de San Pedro del Monte. Agricultura y Ganadería. (fondo 3.50, Lugar- León, expediente 11, foja 1). AGHEG, Guanajuato, Guanajuato, México.

8 Oficio del Subsecretario de Agricultura Jesús Merino Fernández al ingeniero Luis Alonso Trejo”. 6 de abril de 1949. Agricultura y ganadería. (fondo 3.50, lugar-Guanajuato, expediente 6, fojas 2). AGHEG, Guanajuato, Guanajuato, México. Mejía, B. 28 de octubre de 1952. Cuestionario dirigido al agente de la Secretaría de Economía. Agricultura y ganadería. (fondo 3.50, lugar-Guanajuato, expediente 12, fojas 5). AGHEG, Guanajuato, Guanajuato, México.

9 Esqueda, M. 22 de octubre de 1947. Petición al gobierno del estado para la construcción de una presa. Departamento de agricultura, ganadería e irrigación. (caja 1, s/e, fojas 2). Archivo histórico del Estado de Jalisco (en adelante AHEJ). Guadalajara, México.

10 Oficio del Subsecretario de Agricultura Jesús Merino Fernández al ingeniero Luis Alonso Trejo. 6 de abril de 1949. Agricultura y ganadería. (fondo 3.50, lugar-Guanajuato, expediente 6, fojas 2). AGHEG, Guanajuato, Guanajuato, México.

11 Oficio al gobierno del Estado por parte del Instituto Mexicano de Conservación de los Recursos Naturales sobre el Congreso para detener el avance de la erosión de la tierra en México. 10 de diciembre de 1952. Aguas y bosques. (1952-1973, caja 9, expediente 90, foja 26). Archivo General e Histórico del Poder Ejecutivo del Estado de Michoacán, (en adelante AGHPEM), Morelia, México.

12 Ramos Padilla, F. 1956-1957. Informes de labores desarrollado en el distrito de conservación del suelo y agua de la Cuenca del Tepalcatepec a la Dirección General de Conservación del Suelo y Agua de la Comisión del Tepalcatepec. Aguas y bosques. (1956-1972, caja 9, expediente 90, fojas 162). AGHPEM, Morelia, México.

13 Ramos Padilla, F. 1956-1957. Informes de labores desarrollado en el distrito de conservación del suelo y agua de la Cuenca del Tepalcatepec a la Dirección General de Conservación del Suelo y Agua de la Comisión del Tepalcatepec. Aguas y bosques. (1956-1972, caja 9, expediente 90, fojas 162). AGHPEM, Morelia, México. Por ejido se entiende a las posesiones de tierras asignadas por los gobiernos posrevolucionarios, sobre todo por el régimen de Lázaro Cárdenas que distribuyó más de 18 millones de hectáreas en el período 1934-1940. Esas asignaciones tuvieron un aspecto económico y otro político, pues los ejidos y los ejidatarios fueron insertados en el corporativismo mexicano a través de organizaciones vinculadas al partido único oficial. Según las leyes agrarias, los ejidos eran posesiones inalienables.

14 Ramos Padilla, F. 31 de agosto de 1958. Informe de labores desarrollado en el distrito de conservación del suelo y agua de la Cuenca del Tepalcatepec a la Dirección General de Conservación del Suelo y Agua de la Comisión del Tepalcatepec. Aguas y bosques. (1956-1972, caja 9, expediente 90, foja 88). AGHPEM, Morelia, México.

15 Ramos Padilla, F. 1956-1957. Informes de labores desarrollado en el distrito de conservación del suelo y agua de la Cuenca del Tepalcatepec a la Dirección General de Conservación del Suelo y Agua de la Comisión del Tepalcatepec. Aguas y bosques. (1956-1972, caja 9, expediente 90, fojas 162). AGHEG, Guanajuato, Guanajuato, México.

16 Oficio de la Sociedad de Crédito Local de Tingambato a Moisés de la Peña, gerente del Banco Nacional de Crédito Agrícola. 10 de julio de 1956. Agricultura y Ganadería. (1952-1956, caja 2, expediente 11, fojas 2). AGHPEM, Morelia, México.

17 El presidente la Sociedad de Pequeños propietarios de la colonia Emiliano Zapata del municipio de Nahuatzen. 25 de junio de 1956. Agricultura y ganadería. (1955-1956, caja 3, expediente 12, foja 37). AGHPEM, Morelia, México.

18 Méndez Gil, G. 8 de abril de 1952. Oficio de la Delegación General en el Estado de Michoacán de la Confederación Nacional de la Pequeña Propiedad Agrícola al secretario general de Gobierno en el Estado, sobre las fábricas productoras de fertilizantes, "Guanos y Fertilizantes, Reactivos S.A. y Beick Félix". Agricultura y ganadería. (1950-1952, caja 4, expediente 7, foja 293). AGHPEM, Morelia, México.

19 El presidente la Sociedad de Pequeños propietarios de la colonia Emiliano Zapata del municipio de Nahuatzen. 25 de junio de 1956. Agricultura y ganadería. (1955-1956, caja 3, expediente 12, foja 37). AGHPEM, Morelia, México.

20 Según Tamayo, la producción nacional era de 58,649 toneladas en 1958.

21 Tamayo y Martínez tomaron los datos de NAFINSA. La tendencia representa la cantidad de nitrógeno producida por Guanomex y contenida en distintas mezclas fertilizantes. Los fertilizantes y los porcentajes de nitrógeno que se utilizaron para hacer la tabla son: sulfato de amonio $(21 \%$ de $\mathrm{N})$, nitrato de amonio ( $34 \%$ de $\mathrm{N})$, amoniaco anhidro $(82 \% \mathrm{de} \mathrm{N})$. 
Netzahualcóyotl Luis Gutiérrez Núñez. Revolución verde en los suelos agrícolas de México. Ciencia...

22 mientras en 1949 el costo representaba un 6,53\% del ingreso, esto con un rendimiento de 2,500 kilogramos por hectárea, en 1964 significaba el 1,71\%

23 Según el doctor Miguel Nájera Rincón, entomólogo y entomopatólogo, e investigador del INIFAP, en los años ochenta los enfoques microbiológicos del suelo comenzaron a recibir importancia en México. Nájera, M., comunicación personal, 2 de junio, 2017.

\section{BY-NC-SA}

